J Occup Environ Hyg. 2017 May ; 14(5): 368-376. doi:10.1080/15459624.2016.1263391.

\title{
Nonwoven Textile for Use in a Nanoparticle Respiratory Deposition Sampler
}

\author{
Donna J.H. Vosburgh ${ }^{1,}$, Jae Hong Park ${ }^{2}$, Levi W. D. Mines ${ }^{2}$, Imali A. Mudunkotuwa ${ }^{3}, \mathrm{~T}$. \\ Renée Anthony ${ }^{2}$, and Thomas M. Peters ${ }^{2}$ \\ ${ }^{1}$ Department of Occupational and Environmental Safety and Health, University of Wisconsin- \\ Whitewater, Whitewater, Wisconsin, USA \\ ${ }^{2}$ Department of Occupational and Environmental Health, The University of lowa, lowa City, lowa, \\ USA \\ ${ }^{3}$ Department of Chemistry, The University of lowa, lowa City, lowa, USA
}

\section{Abstract}

The nanoparticle respiratory deposition (NRD) sampler is a personal sampler that combines a cyclone, impactor, and a nylon mesh diffusion stage to measure a worker's exposure to nanoparticles. The concentration of titanium in the nylon mesh of the diffusion stage complicates the application of the NRD sampler for assessing exposures to titanium dioxide nanoparticles. This study evaluated commercially available nonwoven textiles for use as an alternative media in the diffusion stage of the NRD sampler. Three textiles were selected as containing little titanium from an initial screening of 11 textiles by field portable x-ray fluorescence (FPXRF). Further evaluation on these three textiles was conducted to determine the concentration of titanium and other metals by inductively coupled plasma - optical emission spectroscopy (ICP-OES), the number of layers required to achieve desired collection characteristics for use as the diffusion stage in the NRD sampler (i.e., the nanoparticulate matter, NPM, criterion), and the pressure drop associated with that number of layers.

Only three (two composed of cotton fibers, $\mathrm{C} 1$ and $\mathrm{C} 2$; and one of viscose bamboo and cotton fibers, BC) of 11 textiles screened had titanium concentrations below the limit of detection the XRF device $\left(0.15 \mu \mathrm{g} / \mathrm{cm}^{2}\right)$. Multiple metals, including small amounts of titanium, were found in each of the three nonwoven textiles using ICP-OES. The number of 25 -mm-diameter layers required to achieve the collection efficiency by size required for the NRD sampler was three for $\mathrm{C} 1\left(\mathrm{R}^{2}=0.95\right.$ with reference to the NPM criterion), two for $\mathrm{C} 2\left(\mathrm{R}^{2}=0.79\right)$, and three for BC $\left(\mathrm{R}^{2}\right.$ $=0.87)$. All measured pressure drops were less than the theoretical and even the greatest pressure drop of 65.4 Pa indicated that a typical personal sampling pump could accommodate any of the three nonwoven textiles in the NRD sampler. The titanium concentration, collection efficiency, and measured pressure drops show there is a potential for nonwoven textiles to be used as the diffusion stage of the NRD sampler.

\footnotetext{
*Corresponding author: Donna J.H. Vosburgh.
} 


\section{Keywords}

nanoparticle; nonwoven; textile; sampler; diffusion

\section{INTRODUCTION}

Airborne nanoparticles-particles with a diameter of at least one dimension smaller than $100 \mathrm{~nm}^{(1)}$-are present in many workplaces. Measuring nanoparticle exposure in the workplace is challenging and has involved multiple types of instruments and sampling strategies. ${ }^{(2)}$ Ideally what is needed is a sampler that fits into current industrial hygiene field sampling methodologies, particularly one that is small enough to be used to assess personal exposures ${ }^{(3)}$, can allow quantification of nanoparticles apart from larger particles that occur in the work environment, and collects nanoparticles with an efficiency that matches respiratory deposition. ${ }^{(4)}$

The nanoparticle respiratory deposition (NRD) sampler is a new personal sampler that was developed to streamline nanoparticle exposure assessment. ${ }^{(4)}$ The NRD sampler is composed of three parts: a 25-mm aluminum respirable cyclone, an impaction stage, and a diffusion stage. The diffusion stage consists of eight nylon mesh screens with a collection efficiency by particle size closely matching the nano-particulate matter (NPM) criterion deposition of nanoparticles smaller than $300 \mathrm{~nm}$. The NPM criterion was developed by Cena et al. ${ }^{(4)}$ from the International Commission on Radiological Protection deposition curve for the average adult under light exercise and nose-breathing conditions ${ }^{(5)}$ and represents the fraction of NPM that can deposit in the respiratory system when inhaled. ${ }^{(4)}$ The NRD sampler is commercially available (ZNRD001, Zefon, UAS) and work has been done to establish a method for using the NRD sampler to evaluating exposure to welding fumes. ${ }^{(6)}$

Although the NRD sampler works well to collect nanoparticles with an efficiency that matches the respiratory system, the nylon mesh screen in the diffusion stage contain high levels of titanium, presumably as titanium dioxide $\left(\mathrm{TiO}_{2}\right)$, used to whiten the nylon. ${ }^{(7)}$ Measuring occupational exposure to nano-sized $\mathrm{TiO}_{2}$ aerosol is of interest for many industrial hygienists because nano-sized $\mathrm{TiO}_{2}$ is used in many commercial products, commonly as a whitener, and has been classified as a potential occupational carcinogen. ${ }^{(8)}$ The mass of collected $\mathrm{TiO}_{2}$ that can be differentiated from the background metal in the collection media, the limit of detection (LOD) of the media, is an important consideration. For a sample collected over eight hours with the $2.5 \mathrm{~L} \mathrm{~min}^{-1} \mathrm{NRD}$ sampler, the diffusion media must contain less than $14.8 \mu \mathrm{g}$ total titanium to quantify airborne nano-sized $\mathrm{TiO}_{2}$ at one-tenth of the National Institute for Occupational Safety and Health (NIOSH) recommended exposure limit (REL) of $0.3 \mathrm{mg} \mathrm{m}^{-3}$. The commercial NRD sampler is not able to be used to measure those occupational exposures because of the large amounts of titanium on the diffusion stage. ${ }^{(7)}$

Nonwoven textiles are a potential media for in the diffusion stage of the NRD sampler. A nonwoven textile is a fabric composed of fibers that are randomly oriented and held together by means other than weaving or knitting. ${ }^{(9)}$ Nonwoven textiles can be composed of a variety of materials including natural fibers, such as cotton, and manmade fibers, such as polyester. 
The collection efficiency of nonwoven textiles depends on the textile characteristics of basis weight, fiber diameter, material thickness, and material fiber density. ${ }^{(10)}$ Basis weight is a textile term that refers to the mass of a surface area of fabric. ${ }^{(11)}$ The packing density of nonwoven textiles varies and may be low enough to allow for the diffusion stage to match the NPM criterion while remaining small enough to fit in the NRD sampler.

In this study, we investigated the use of nonwoven textiles in the diffusion stage of the NRD sampler. For the nonwoven textiles to be useful in the NRD sampler, they would have to have either no or a very low concentration of titanium, an aerosol collection efficiency that matched the NPM criterion, and a pressure drop small enough that a personal pump could be used. We first screened a variety of commercially available textiles for titanium using field portable X-ray fluorescence (FPXRF). On selected nonwoven textiles below the LOD of the FPXRF, additional testing was conducted. The physical characteristics of the nonwoven textiles (basis weight, fiber diameter, textile thickness, and material density) were determined and used to theoretically estimate the quantity of each nonwoven textile needed to achieve the required particle collection efficiency in the $2.5 \mathrm{~L} \mathrm{~min}^{-1} \mathrm{NRD}$ sampler along with the pressure drop caused by that amount of nonwoven textile. The metals content was measured by traditional digestion and metals analysis methods. Then the measured collection efficiency and pressure drop for the selected nonwoven textiles was determined in laboratory experiments.

\section{METHODS}

As presented in Table I, eleven nonwoven textiles (i.e., quilt battings) were selected as inexpensive, readily-available nonwoven textiles with the potential to replace the nylon mesh in the diffusion stage of the NRD sampler. Manufactured by two companies (Quilters Dream Batting, Virginia Beach, VA; and Pellon Consumer Products, Clearwater, FL), these nonwoven textiles represent a cross-section of available batting colors (five white, one black, and five off-white) and composition (four polyester, two wool, two cotton, two mixed, one fire-retardant fibers). These nonwoven textiles were produced by needle-punching, a process to mechanical interlock the fibers and hold them together without adhesive.

A FPXRF (Niton XL3t Ultra, Thermo Scientific, Waltham, MA, USA) was used to screen nonwoven textiles for titanium. Nonwoven textiles with titanium compositions greater than LOD of the FPXRF were removed from further testing. The limit of detection of titanium for the FPXRF is $0.15 \mu \mathrm{g} / \mathrm{cm}^{2}$. The FPXRF was set to thin film standard filter mode with a sample duration of 120 seconds (main range: 40 seconds, low range: 40 seconds, and high range: 40 seconds). Three measurements (upper left corner, middle, lower right corner) were taken on one piece $(5.1 \mathrm{~cm} \times 5.1 \mathrm{~cm})$ of each of the 11 nonwoven textiles.

\section{Physical Characterization}

The nonwoven textiles selected for further evaluation were characterized physically to determine the textile thickness, basis weight, fiber material density, and fiber diameter of each nonwoven textile so that the collection efficiency of particles smaller than $300 \mathrm{~nm}$ and pressure drop could be estimated from filtration theory. The uncompressed thickness of each textile was measured with a caliper. The basis weight of ten squares $(5.1 \mathrm{~cm} \times 5.1 \mathrm{~cm})$ of the 
nonwoven textile was calculated as the weight divided by the surface area of the square $\left(25.8 \mathrm{~cm}^{2}\right)$. Fiber material densities were obtained from literature. ${ }^{(12,13)}$ For nonwoven textiles containing fibers of mixed fiber composition, the fiber material density was calculated based on the percentages of fibers listed by the manufacturer.

The diameter of individual fibers in each nonwoven textile was determined using scanning electron microscopy (SEM) (S4800, Hitachi-High Technologies Corporation, Japan). Each nonwoven textile $(1 \mathrm{~cm} \times 1 \mathrm{~cm})$ was placed on a stub and introduced inside a Sputter Coater (K550X, Quorum Technologies Ltd, UK) where a thin layer of Au/Pd (80\%/20\%) was deposited on to the nonwoven textile surface. This step was conducted in order to prevent excessive charging of the nonwoven textile during the analysis. Once the coating is complete, the nonwoven textile was imaged with $5.0 \mathrm{kV}$ accelerating voltage and ImageJ (US National Institutes of Health, US) was used in image processing.

\section{Theoretical Collection Efficiency}

Filtration theory was used to determine the number of layers of each nonwoven textile required in the commercial NRD sampler (which is designed for a flow of $2.5 \mathrm{~L} \mathrm{~min}^{-1}$ and a cassette diameter of $25 \mathrm{~mm}$ ) for the sampler to achieve the NPM criterion. First the collection efficiency by particle diameter for one layer of each nonwoven textile was determined using the physical characteristics of each nonwoven textile. Then additional layers of nonwoven textile were added into the theory until the theoretical collection efficiency by particle size was close to the NPM criterion. The physical characteristics of the nonwoven textiles were applied to filtration theory when the solid volume fraction was estimated for nonwovens using Payen et al. ${ }^{(10)}$ :

$$
\alpha=100 \frac{G}{L \rho_{f}}
$$

where $G$ is the basis weight of the nonwoven textile, $L$ is the nonwoven textile thickness, and $\rho_{f}$ is the fiber material density.

Following Raynor et al. ${ }^{(14)}$ the theoretical collection efficiency by particle diameter $\left(E_{T}\right)$ of the three selected nonwoven textiles was computed as:

$$
E_{T}=1-\exp \left(\frac{-4 E_{F} \alpha L}{\pi d_{f}}\right)
$$

where $E_{F}$ is the single fiber efficiency, $a$ is the solid volume fraction calculated using equation 1 , and $d_{f}$ is the fiber diameter. $E_{F}$ was calculated as:

$$
E_{F}=E_{D}+E_{R}
$$


where $E_{D}$ is the single fiber efficiency due to diffusion and $E_{R}$ is the single fiber efficiency due to interception. The effects of inertial impaction and gravitational settling were neglected because particles of interest were smaller than $300 \mathrm{~nm}$. The single fiber efficiency $E_{D}$ was calculated as:

$$
E_{D}=1.6\left(\frac{1-\alpha}{K u}\right) P e^{-\frac{2}{3}} C c_{(d)}
$$

where $P e$ is the Peclet number ${ }^{(14)}, K u$ is the Kuwabara hydrodynamic factor ${ }^{(14)}$, and $C_{C(d)}$ is the Cunningham slip correction factor calculated as:

$$
C_{C(d)}=1+0.388 K n_{f}\left(\frac{(1-\alpha) P e}{K u}\right)^{\frac{1}{3}}
$$

In Equation 5, $K n_{f}$ is the Knutsen number of the nonwoven textile fiber. $E_{R}$ was calculated as:

$$
E_{R}=\left(\frac{1+R}{2 K u}\right)\left[2 \ln (1+R)-1+\alpha+\left(\frac{1}{1+R}\right)^{2}\left(1-\frac{\alpha}{2}\right)-\left(\frac{\alpha}{2}\right)(1-R)^{2}\right]
$$

where $R$ is the ratio of the particle diameter to the particle fiber. A flow rate of $2.5 \mathrm{~L} \mathrm{~min}^{-1}$ was used to match that of the NRD sampler. ${ }^{(3)}$

Because the diffusion stage is downstream of the impactor in the NRD, the theoretical collection efficiency from above was adjusted $\left(E_{t, a d j(d)}\right)$ to account for collection that occurs in the impaction stage as:

$$
E_{t, a d j(d)}=E_{t(d)} P_{i m p(d)}
$$

where $P_{\operatorname{imp}(d a)}$ is the penetration through the impaction stage. $P_{\text {imp (da) }}$ was calculated as ${ }^{(15)}$ :

$$
\begin{gathered}
P_{i m p(d a)}=1+\frac{\ln \left(d_{a} 10^{6}\right)}{8.65}+0.15, d_{a} \leq 133.3 \mathrm{~nm} \\
P_{\text {imp }(d a)}=1-0.46\left(1+\operatorname{erf}\left(\frac{\ln \left(\frac{d_{a} 10^{6}}{0.45}\right)}{\sqrt{2} \ln (1.43)}\right)\right)-0.08, d_{a}>133.3 \mathrm{~nm}
\end{gathered}
$$

where $d_{a}$ is the aerodynamic diameter in meters. The $d_{a}$ was converted to the mobility diameter, $d$, using Equations 10 and $11^{(16)}$ : 


$$
\begin{gathered}
d_{v}=d_{a} \sqrt{\frac{\chi \rho_{0} C c_{\left(d_{a}\right)}}{\rho_{p} C c_{\left(d_{v}\right)}}} \\
d=d_{v} \frac{\chi C c_{(d)}}{C c_{\left(d_{v}\right)}}
\end{gathered}
$$

where $d_{V}$ is the volumetric diameter, $\chi$ is the dynamic shape factor ( $\chi$ was assumed to be 1.08 for salt particles $\left.{ }^{(16)}\right), \rho_{O}$ was the unit density $\left(1000 \mathrm{~kg} \mathrm{~m}^{-3}\right)$ and $\rho_{p}$ was assumed to be $2200 \mathrm{~kg} \mathrm{~m}^{-3}$ for salt particles. ${ }^{(16)}$

\section{Experimental Collection Efficiency}

For each of the selected nonwoven textiles, the collection efficiency by particle size for the textile specific number of layers computed from theory, was measured using the set up shown in Figure 1. Discs with diameters of $25 \mathrm{~mm}$ were cut from sheets of the nonwoven textiles and fixed in a holder (25-mm conductive polypropylene cassette). A nebulizer (Aeroneb Solo, Aerogen, Dangan, Ireland) was used to aerosolize a solution of $0.1 \% \mathrm{NaCl}$. The test aerosol was neutralized with a Kr-85 aerosol neutralizer (3054A, TSI Incorporated, Shoreview, MN), dried with a diffusion dryer, and then delivered into a $200 \mathrm{~L}$ coagulation chamber to. A fast mobility particle sizer (FMPS) (Model 3091, TSI Incorporated, Shoreview, MN) was used to measure the particle number concentration by mobility size using a 3-way valve to alternate without (WO) or with (W) the layer or layers of nonwoven textile being tested inline before the FMPS in the following sequence: $W O_{1}, W_{1}, W O_{2}, W_{2}$, $W O_{3}, W_{3}, W O_{4}$. The sampling airflow rate of the FMPS was $10 \mathrm{~L} \mathrm{~min}^{-1}$, comprised of the $2.5 \mathrm{~L} \mathrm{~min}^{-1}$ through the nonwoven textile plus $7.5 \mathrm{~L} \mathrm{~min}^{-1}$ of clean HEPA-filtered air. The collection efficiency $\left(E_{\exp (d)}\right)$ of each nonwoven textile was calculated by using equation 12 .

$$
E_{\exp (d)}=1-\left[\frac{W_{1}}{\left(W O_{1}+W O_{2}\right) / 2}+\frac{W_{2}}{\left(W O_{2}+W O_{3}\right) / 2}+\frac{W_{3}}{\left(W O_{3}+W O_{4}\right) / 2}\right] / 3
$$

The measured collection efficiency was then adjusted $\left(E_{\text {exp,adj(d) }}\right)$ to account for collection that occurred in the impaction stage of the NRD using equation 13

$$
E_{\exp , a d j(d)}=E_{\exp (d)} P_{i m p(d)}
$$

\section{Data Analysis}

The adjusted measured collection efficiency was compared to the NPM criterion and the adjusted measured collection efficiency was also compared to the adjusted theoretical collection efficiency by calculating $R^{2}$ values. The $R^{2}$ of the $E_{\text {exp,adj(d) }}$ and the NPM curve 
was calculated using equation 14 where $E_{\text {exp,adj(d),avg }}$ is the mean of the adjusted measured collection efficiency.

$$
R_{\text {exp }, a d j(d)-N P M}^{2}=1-\frac{\sum\left(E_{\text {exp }, a d j(d)}-\mathrm{NPM}_{(d)}\right)^{2}}{\sum\left(E_{\text {exp }, a d j(d)}-E_{\text {exp }, a d j(d), a v g}\right)^{2}}
$$

The $R^{2}$ of the $E_{\text {exp,adj(d) }}$ and $E_{t h, a d j(d)}$ was calculated using equation 15 .

$$
R_{e x p, a d j(d)-a d j(d)}^{2}=1-\frac{\sum\left(E_{\exp , a d j(d)}-E_{a d j(d)}\right)^{2}}{\sum\left(E_{\exp , a d j(d)}-E_{\exp , a d j(d), a v g}\right)^{2}}
$$

\section{Pressure Drop}

The pressure drops across each of the nonwoven textiles, $\Delta P$, was calculated for a flow rate of $2.5 \mathrm{~L} \mathrm{~min}^{-1}$ as:

$$
\Delta P=\frac{16 \eta \alpha U L}{K u d_{f}^{2}}
$$

where $\mu_{a}$ is the viscosity of air and $U$ is the airflow rate. ${ }^{(14)}$

For each of the three selected nonwoven textiles, the pressure drop across one layer was experimentally determined by connecting a digital manometer (Series 475 Mark III, Dwyer Instruments, Inc., Michigan City, IN) upstream and downstream of a 25-mm conductive cassette while air was pulled through the cassette at $2.5 \mathrm{~L} \mathrm{~min}^{-1}$. All measurements were conducted in triplicate.

\section{Traditional Chemical Characterization}

Inductively coupled plasma with optical emission spectroscopy (ICP-OES; model $720 \mathrm{ES}$, Varian, Inc., US) was used to measure the levels of titanium, chromium, manganese, iron, copper, and zinc in each of the three selected nonwoven textiles. As described in detail by Mudunkotuwa et al. ${ }^{(17)}$, a sample of textile $(\sim 200-400 \mathrm{mg})$ was inserted into a digestion vessel containing concentrated $\mathrm{H}_{2} \mathrm{SO}_{4}(4 \mathrm{~mL})$ and concentrated $\mathrm{HNO}_{3}(2 \mathrm{~mL})$. The vessel was then placed in a microwave digestion system (MARS 6, CEM Corporation, USA). The temperature was ramped to $210^{\circ} \mathrm{C}$, held for 45 minutes, and allowed to cool to room temperature. The resulting clear solution was then topped to $25 \mathrm{~mL}$ with water and analyzed. All measurements were conducted in triplicate.

Once the number of layers of each of the selected nonwoven textiles were verified by experimental collection efficiency, the LOD of each of the nonwoven textiles and each 
element were calculated. The LOD was calculated by calculating the value three standard deviations of metal in the blank above the mean ICP-OES determined metal value in the pristine nonwoven textiles. ${ }^{(6)}$

\section{RESULTS}

Of the eleven nonwoven textiles, only three nonwoven textiles had titanium concentrations below the LOD for the FPXRF (Table I). All of the nonwoven textiles that were white or black in color had titanium concentrations above the LOD of the FPXRF. The three nonwoven textiles that had titanium concentrations below the FPXRF LOD were composed of natural cotton fibers or cotton blended with viscose bamboo fibers.

The characteristics of thickness, mean basis weight, and fiber material density of the three selected nonwoven textiles are shown in Table II. Since the BC nonwoven textile was composed of $50 \%$ viscose bamboo and $50 \%$ cotton, the mean of cotton ${ }^{(12)}$ and viscose bamboo $^{(13)}$ was used for the fiber material density of the $\mathrm{BC}$ nonwoven textile. The results of fiber diameter determined by SEM are shown in Figure 2. The mean diameters range from $10.8 \mu \mathrm{m}$ to $12.1 \mu \mathrm{m} . \mathrm{C} 1$ and $\mathrm{C} 2$ are composed of only fibers that are not cylindrical, while $\mathrm{BC}$ has both cylindrical and twisted, crimped fibers. Long and twisted fibers with convolutions, or crimps, in the middle of the fiber are typical of cotton fibers. ${ }^{(11)}$

The size distribution of the salt test aerosol used to determine the measured collection efficiency of the selected nonwoven textiles is shown in Figure 3. The distribution of the test particles was lognormally distributed. The number mean and mode diameters were near 100 $\mathrm{nm}$. The concentration and sized distribution of the test particles were stable during the experiment.

Adjusted collection efficiencies measured experimentally and theoretically compared to the NPM criterion are provided in Figure 4. Each textile required a different number of layers to achieve the NPM criterion. Nonwoven textile $\mathrm{C} 1$ required three layers, $\mathrm{C} 2$ required two layers, and $\mathrm{BC}$ required three layers to achieve good alignment with the NPM criterion. The shape of the measured collection efficiency for the required number of layers matched well with the NPM criterion. The adjusted measured collection efficiencies of the nonwoven textiles had good alignment with the NPM criterion with $\mathrm{R}^{2}$ values of 0.95 for $\mathrm{C} 1,0.79$ for $\mathrm{C} 2$, and 0.88 for $\mathrm{BC}$. The adjusted measured collection efficiencies of the nonwoven textiles to the theory had $\mathrm{R}^{2}$ values of 0.93 for $\mathrm{C} 1,0.88$ for $\mathrm{C} 2$, and 0.79 for $\mathrm{BC}$.

The theoretical pressure drop for one layer of each nonwoven textile was 19.2 Pa for $\mathrm{C} 1$, 32.7 Pa for $\mathrm{C} 2$, and 17.6 Pa for $\mathrm{BC}$. The measured pressure drops of each of the three nonwoven textiles were 15.8 $\mathrm{Pa}, 21.6 \mathrm{~Pa}$, and 13.3 Pa respectively. All of the measured pressure drops were less than the theoretical pressure drops. The pressure drop for one layer of $\mathrm{C} 2$ was the greatest, which agrees with the nonwoven textile characteristics (Table II) in that $\mathrm{C} 2$ was the thickest and had the largest basis weight. The total pressure drop for a diffusion stage composed of three layers of $\mathrm{C} 1$ was estimated at $57.7 \mathrm{~Pa}$, two layers of $\mathrm{C} 2$ at 65.4 $\mathrm{Pa}$, and three layers of $\mathrm{BC}$ at $52.7 \mathrm{~Pa}$.

\footnotetext{
JOccup Environ Hyg. Author manuscript; available in PMC 2018 May 01.
} 
The ICP-OES results showed titanium in the nonwoven textiles. The titanium amounts listed in Table II equate to the mean amounts per one $25 \mathrm{~mm}$ circle of each of the nonwoven textiles; $0.26 \mu \mathrm{g}$ for $\mathrm{C} 1,1.93 \mu \mathrm{g}$ for $\mathrm{C} 2$, and $0.72 \mu \mathrm{g}$ of titanium for the $\mathrm{BC}$. The calculated LOD of the three nonwoven textiles were as follows: $0.78 \mu \mathrm{g}$ for three layers of $\mathrm{C} 1,6.5 \mu \mathrm{g}$ for two layers of $\mathrm{C} 2$, and $2.8 \mu \mathrm{g}$ for three layers of $\mathrm{BC}$.

\section{DISCUSSION}

Nonwoven textiles have the potential to serve as the media in the diffusion stage of the NRD sampler. The calculated LOD of titanium for the three selected nonwoven textiles after screening was substantially less than the $14.8 \mu \mathrm{g}$ target value. The adjusted measured collection efficiency for all three nonwoven textiles was relatively close to the NPM (Figure 4) with $R^{2}$ values close to 1 . The pressure drop per diffusion stage for each nonwoven textile was sufficiently small that any of the three materials could be used in the NRD sampler with a personal pump. ${ }^{(4)}$

To ensure nonwoven textiles met the requirement for titanium composition (less than one tenth of the REL), the target amount in the diffusion stage of an NRD sampler required an amount less than $14.8 \mu \mathrm{g}$ titanium background. Although the FPXRF did not detect any titanium in three nonwoven textiles, the ICP-OES detected titanium in these materials (Table II). The amounts of the other measured metals in the nonwoven textiles were, in some cases, considerable: except for chromium in $\mathrm{C}$, the metals concentrations in one nonwoven textile layer were greater than the estimated limit of detection for NIOSH method 7300, ${ }^{(18)}$ indicating significant background contamination potential. The metal content of the nonwoven textiles would limit their use in certain occupational areas such as assessing welding fume exposure, which has already been identified as a potential use of the NRD sampler. ${ }^{(6)}$

The adjusted collection efficiency and pressure drops measured experimentally for all selected textiles were compatible for use in the NRD sampler. However, a nonwoven textile specifically developed for the NRD sampler may be needed. If natural fibers are used, the fiber shape may influence the collection efficiency in a way that may be unpredictable. Natural fibers that are long enough to be used in a nonwoven textile will not be perfectly cylindrical, and in some cases, such as with cotton, may be twisted and have many convolutions. ${ }^{(11)}$ Natural fibers that have been processed, such as viscose bamboo fibers, may provide better agreement due to the cylindrical structure of the fibers. ${ }^{13)}$ An alternative is to use newer techniques to create cylindrical fibers, such as electrospinning. ${ }^{(19,20)}$ Future research is need to determine the influence of the fiber shape on collection efficiencies for diffusion layers in the NRD.

Before a nonwoven textile could be used in the NRD sampler, there are limitations that must be addressed. First, commercially available nonwoven materials with other intended purposes, such as the nonwoven textiles used in this study, may have variability in the product that could affect the homogeneity of the material. That variability has the potential of influencing the collection efficiency of a material. More work is needed to address the issue of humidity and fiber diameter for potential nonwoven fabrics. Natural fibers and hairs 
were previously evaluated as an aerosol collection substrate ${ }^{(21)}$, but these authors identified a change in fiber characteristics with humidity. Some manmade fibers are more stable in their diameters with regard to humidity changes than others. Viscose bamboo has been shown to be to swell when wet, thereby increasing the fiber diameter, which may reasonably affect collection efficiency. However it is unknown if the fibers would absorb enough moisture from humidity to significantly increase their diameters. ${ }^{(13)}$ Particles smaller than $25 \mathrm{~nm}$ were not used when evaluating collection efficiencies of the nonwoven textiles. A workplace may have a significant amount of nanoparticles with diameters $\leq 25 \mathrm{~nm}$ so additional collection efficiency assessments are recommended in this size range.

\section{CONCLUSION}

This work demonstrates that some nonwoven textiles are sufficiently free of metals contamination and can be used to achieve required collection characteristics for use as the diffusion stage of the NRD sampler. Three of eleven commercially available nonwoven textiles were selected to potentially replace the nylon mesh in the diffusion stage of the NRD sampler based on low metals content determined by FPXRF. The selected textiles can be used to achieve adjusted collection efficiencies compatible with the NPM criterion and at pressure drops sufficiently small for use with personal, belt-mounted sampling pumps. Although titanium was not detected in the three nonwoven textiles by FPXRF, it was detected by with the more sensitive ICP-OES. The LOD for all three of the materials were below the target value of $14.8 \mu \mathrm{g}$. However considerable amounts of other metals were detected in all of the three materials. The metal content of these commercially available nonwoven textiles would limit their use in assessing exposures to many common metals.

\section{Acknowledgments}

This research was funded by support from the National Institute for Occupational Safety and Health (R01 OH010238).

\section{References}

1. ASTM Standard E2456. Standard Terminology Relating to Nanotechnology. ASTM International; West Conshohocken, PA: 2006. www.astm.org

2. Ramachandran G, Ostraat M, Evans DE, Methner MM, O'Shaughnessy P, D'Arcy JD, Geraci CL, Stevenson E, Maynard A, Rickabaugh K. A Strategy for Assessing Workplace Exposures to Nanomaterials. Journal of Occupational and Environmental Hygiene. 2011; 8:673-685. [PubMed: 22023547]

3. Department of Health and Human Services, National Institute for Occupational Safety and Health. NIOSH Manual of Analytical Methods, Second Supplement, Chapter E-Development and Evaluation of Methods. 1998. (DHHS (NIOSH) Publication No. 98-119)Retrieved from http:// www.cdc.gov/niosh/docs/2003-154/pdfs/chapter-e.pdf

4. Cena LG, Anthony TR, Peters TM. A Personal Nanoparticle Respiratory Deposition (NRD) Sampler. Environ Sci Technol. 2011; 45:6483-6490. [PubMed: 21718022]

5. International Commission on Radiological Protection (ICRP). Human Respiratory Tract Model for Radiological Protection. Elsevier Science, Ltd.; Oxford, U.K: 1994. Publication 66

6. Cena LG, Keane MJ, Chisholm WP, Stone S, Harper M, Chen BT. A Novel Method for Assessing Respiratory Deposition of Welding Fume Nanoparticles. Journal of Occupational and Environmental Hygiene. 2014; 11:771-780. [PubMed: 24824154] 
7. Mines LWD, Park JH, Mudunkotuwa IA, Anthony TR, Grassian VH, Peters TM. Porous Polyurethane Foam for Use as a Particle Collection Substrate in a Nanoparticle Respiratory Deposition Sampler. Aerosol Science and Technology. 2006; 50:497-506.

8. Department of Health and Human Services, National Institute for Occupational Safety and Health. Current Intelligence Bulletin 63 Occupational Exposure to Titanium Dioxide. 2011. (DHHS (NIOSH) Publication No. 2011-160)Retrieved from http:/www.cdc.gov/niosh/docs/2011-160/pdfs/ 2011-160.pdf

9. INDA Association of the Nonwoven Fabrics Industry. INDA. Cary, NC: 2002. INDA Nonwoven Glossary.

10. Payen J, Vroman P, Lewandowski M, Perwuelz A, Calle-Chazelet S, Thomas D. Influence of fiber diameter, fiber combinations and solid volume fraction on air filtration properties in nonwovens. Textile Research Journal. 2012; 82:1948-1959.

11. Morton, WE., Hearle, JWS. Physical properties of textile fibres. 4th. Woodhead Publishing Limited; Cambridge: 2008.

12. Zupin, Z., Dimitrovski, K. Mechanical Properties of Fabrics from Cotton and Biodegradable Yarns Bamboo, SPF, PLA in Weft. In: Dubrovski, PD., editor. Woven Fabric Engineering. InTech; 2010. p. 25-46.

13. Lipp-Symonowicz B, Sztajnowski S, Wojciechowska D. New Commercial Fibres Called 'Bamboo Fibres'-Their Structure and Properties. Fibres \& Textiles in Eastern Europe. 2011; 19:18-23.

14. Raynor, PC., Leith, D., Lee, KW., Mukund, R. Sampling and Analysis Using Filters. In: Kulkarni, P.Baron, P., Willeke, K., editors. Aerosol Measurements. 3rd. Hoboken, New Jersey: John Wiley \& Sons, Inc.; 2011. p. 107-128.

15. Park JH, Mudunkotuwa IA, Mines LWD, Anthony TR, Grassian VH, Peters TM. A granular bed for use in a nanoparticle respiratory deposition sampler. Aerosol Science and Technology. 2015; 49:179-187. [PubMed: 26900208]

16. Hinds, WC. Aerosol Technology. 2nd. John Wiley and Sons, Inc.; New York: 1999.

17. Mudunkotuwa I, Anthony TR, Grassian V, Peters TM. Accurate Quantification of TiO2 Nanoparticles Collected on Air Filters Using a Microwave-Assisted Acid Digestion Method. Journal of Occupational and Environmental Hygiene. 2015; :1-28. DOI: 10.1080/15459624.2015.1072278 [PubMed: 24918755]

18. Department of Health and Human Services, National Institute for Occupational Safety and Health. NIOSH Manual of Analytical Methods, Third Supplement. 2003. (DHHS (NIOSH) Publication No. 2003-154)Retrieved from http://www.cdc.gov/niosh/docs/2003-154/

19. Wang N, Raza A, Si Y, Yu J, Sun G, Ding B. Tortuously structured polyvinyl chloride/polyurethane fibrous membranes for high-efficiency fine particle filtration. Journal of Colloid and Interface Science. 2013; 398:240-246. [PubMed: 23489615]

20. Yun KM, Hogan CJ Jr, Matsubayashi Y, Kawabe M, Iskandar F, Okuyama K. Nanoparticle filtration by electrospun polymer fibers. Chemical Engineering Science. 2007; 62:4751-4759.

21. Jackson GW, James DF. The Permeability of fibrous porous media. The Canadian Journal of Chemical Engineering. 1986; 64:364-374. 
a)

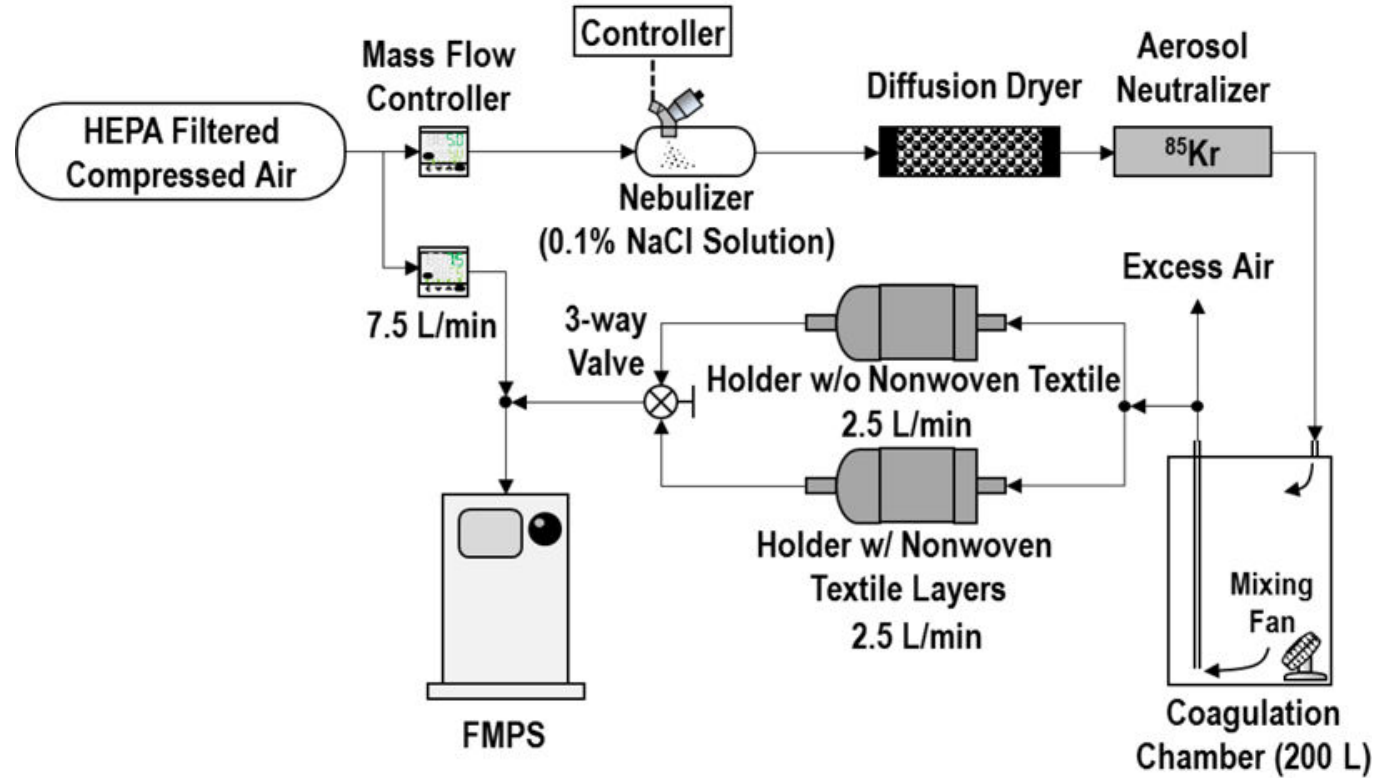

b)

Sampler

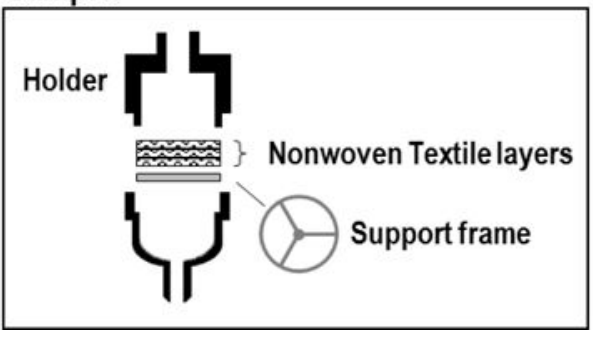

FIGURE 1.

Evaluation of particle collection efficiency of nonwoven textiles: a) experimental set up b) diagram of sampler. 
a) Nonwoven textile $\mathrm{C} 1: 10.8 \mu \mathrm{m}(5.7)$

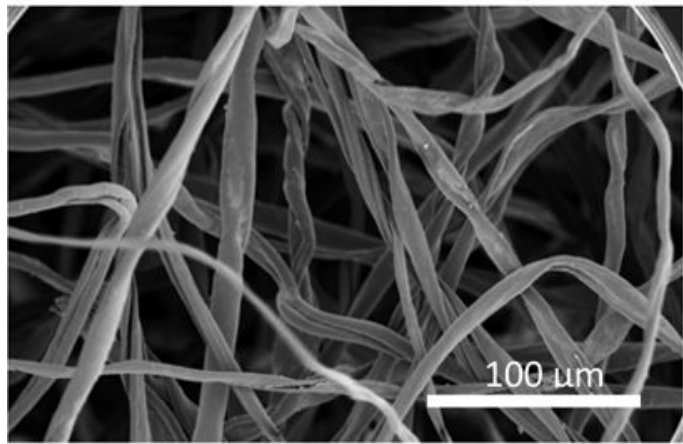

b) Nonwoven textile $\mathrm{C} 2: 11.4 \mu \mathrm{m}(3.7)$

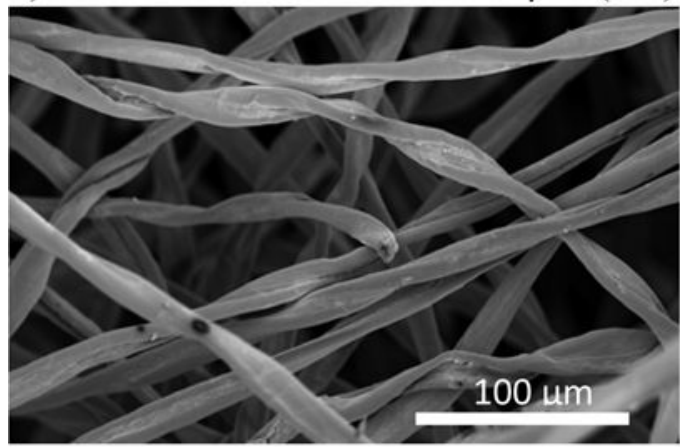

c) Nonwoven texitle BC: $12.1 \mu \mathrm{m}(3.3)$

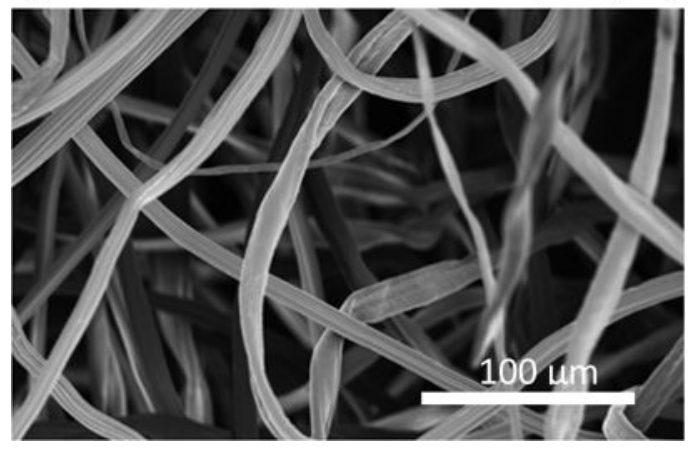

FIGURE 2.

Scanning electron microscopy images, with the mean (standard deviation) of one fiber diameter, of the three nonwoven textiles: a) Quilters Dream Cotton, $\mathrm{C} 1$; b) Pellon Natural Cotton, C2; and c) Pellon Viscose Bamboo, BC. 


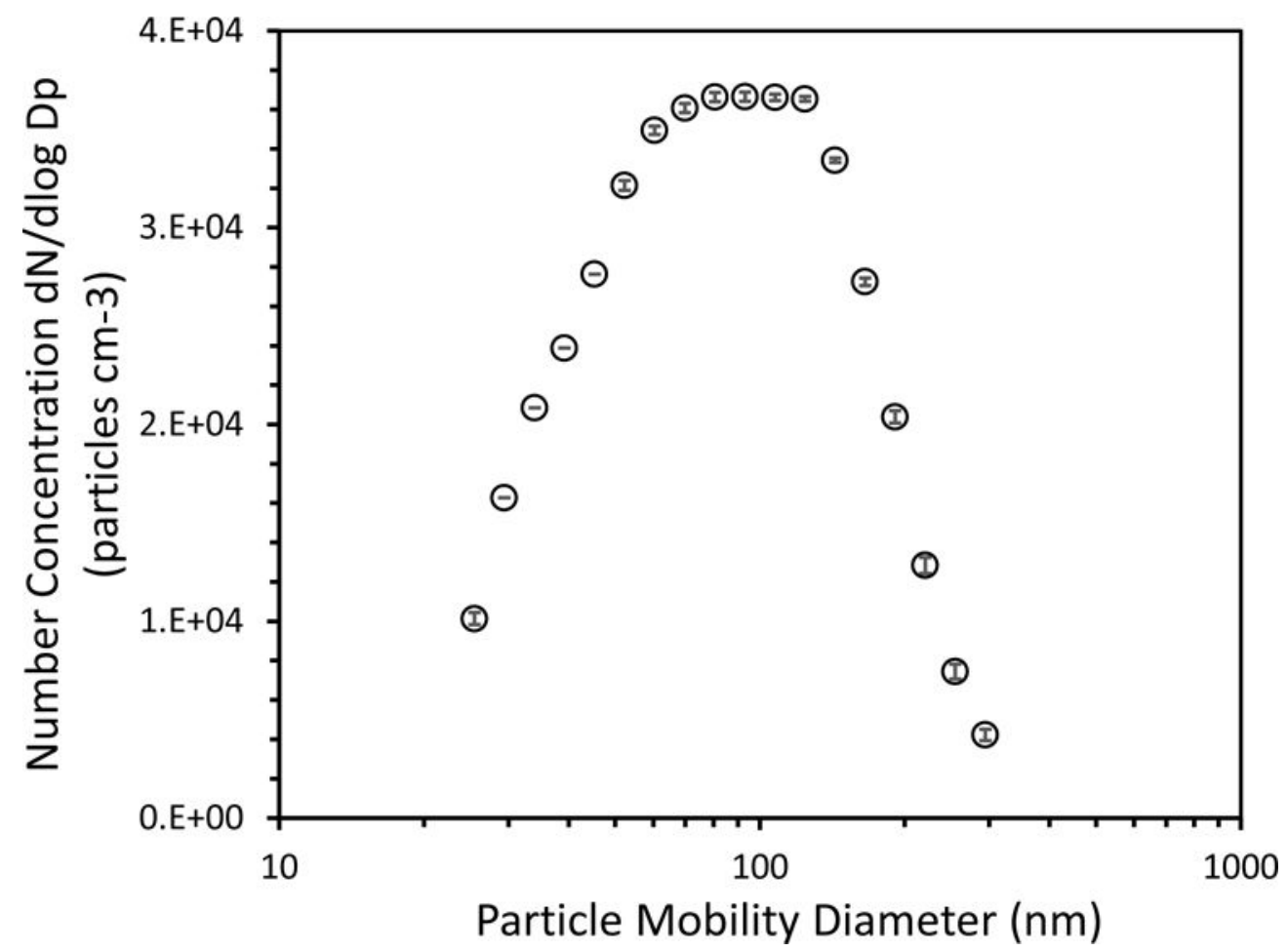

FIGURE 3.

Particle number concentration by particle mobility diameter for salt aerosol used to test efficiency of nonwoven textiles. Error bars represent one standard deviation of twelve measurements. 
a)

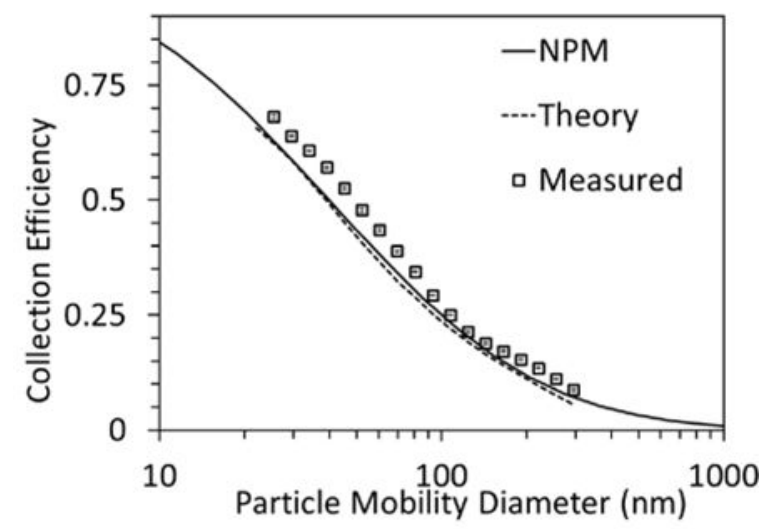

b)

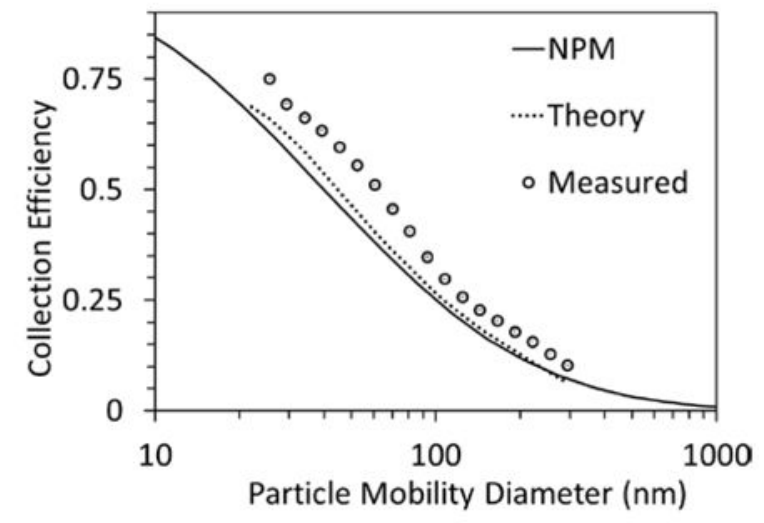

c)

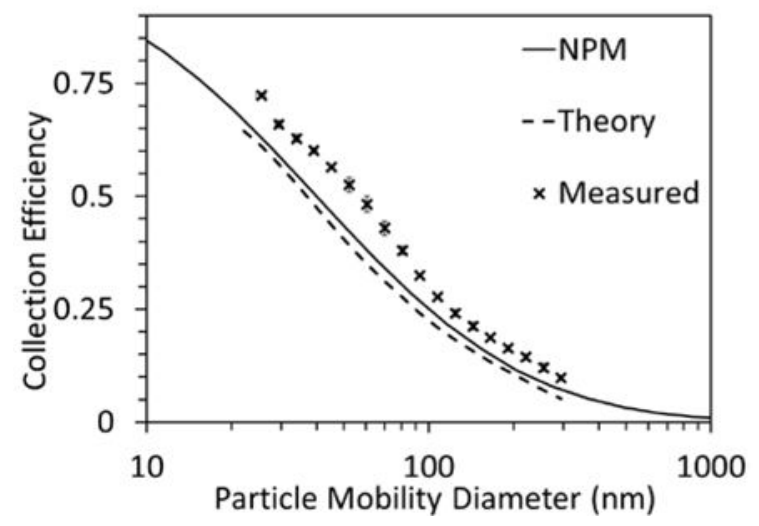

Figure 4.

Impactor adjusted theoretical (dashed) and measured (symbol) collection efficiencies of three nonwoven textiles: a) Quilters Dream Cotton, C1; b) Pellon Natural Cotton, C2; and c) Pellon Viscose Bamboo, BC. The standard deviation of the measured collection efficiency was small. The error bars representing one standard deviation fit within the symbol. 


\section{Table I}

Titanium content measured by field portable x-ray florescence (FPXRF) for 11 nonwoven textiles.

\begin{tabular}{lccc} 
Color & Brand Name, Identifier & Material & Mean FPXRF Titanium Result $\boldsymbol{a}^{\left(\boldsymbol{\mu g} \mathbf{g}^{\mathbf{- 1}}\right)}$ \\
\hline White & Quilters Dream Poly Request Loft, P1 & Polyester & 11.9 \\
\hline White & Quilters Dream Puff, P2 & Polyester & 8.1 \\
\hline White & Pellon Polyester, P3 & Polyester & 7.8 \\
\hline White & Quilters Dream Blend Select Loft, CP & 70\% Cotton 30\% Polyester & 8.4 \\
\hline White & Quilters Dream Angel Request Loft, A1 & Fire-Retardant Fibers & 5.6 \\
\hline Black & Quilters Dream Poly Request Loft, P4 & Polyester & 8.6 \\
\hline Off-White & Quilters Dream Wool, W1 & Wool & 3.3 \\
\hline Off-White & Pellon Wool, W2 & Wool & 2.9 \\
\hline Off-White & Quilters Dream Cotton Request Loft, C1 & Cotton & LOD $^{b}$ \\
\hline Off-White & Pellon Natural Cotton, C2 & Cotton & LOD $^{b}$ \\
\hline Off-White & Pellon Viscose Bamboo Blend, BC & $\mathbf{5 0 \%}$ Bamboo 50\% Cotton & LOD $^{b}$ \\
\hline
\end{tabular}

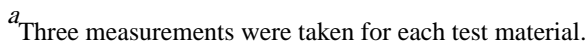

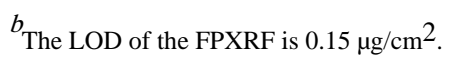

Bold indicates that the material was selected for further analysis. Quilters Dream textiles from Quilters Dream Batting, Virginia Beach, VA Pellon textiles from Pellon Consumer Products, Clearwater, FL 


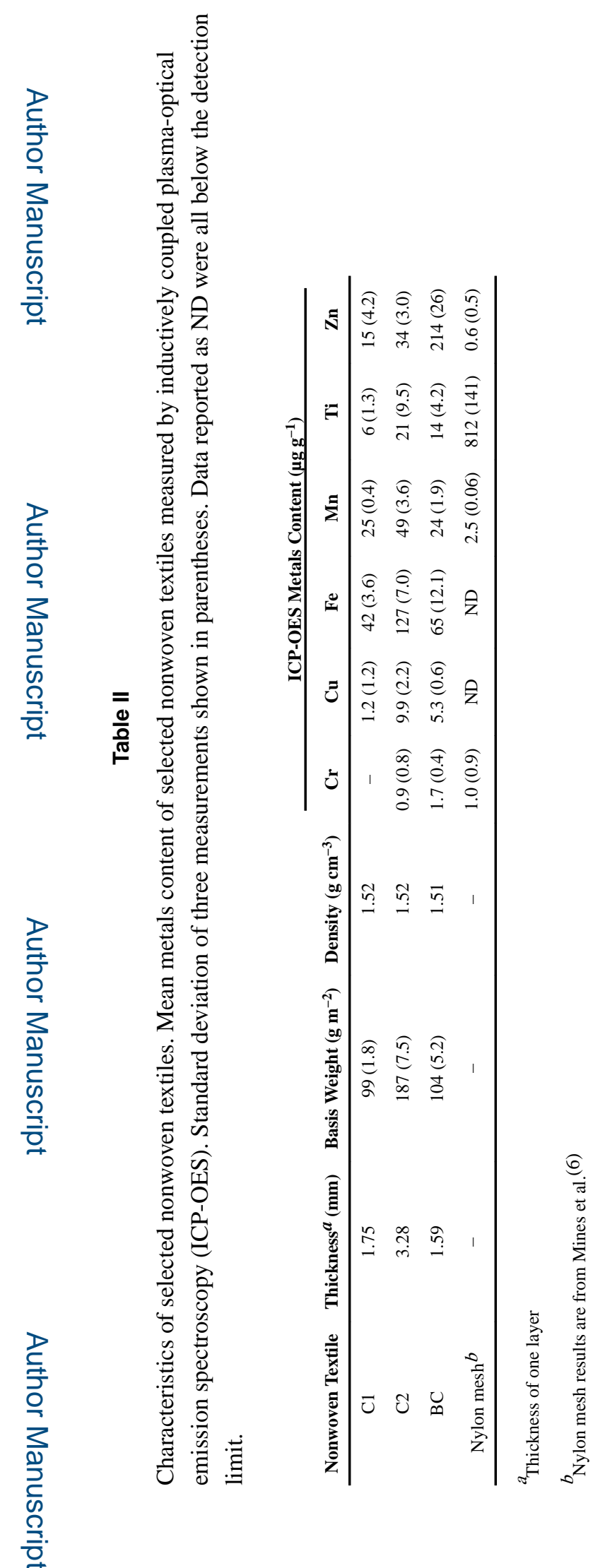

